\title{
Implementation of a methodology to define the optimum capacity of a wind farm
}

\author{
Paulo Pinto $^{1,2}$, Miguel Ferreira ${ }^{2}$, Álvaro Rodrigues ${ }^{2,3}$ \\ ${ }^{1}$ IPB - Instituto Politécnico de Bragança \\ Campus de Santa Apolónia, Apartado 1345300 Bragança (Portugal) \\ phone: +351 273303 154, fax: +351 273313 051, e-mail: pp@ipb.pt. \\ 2 INEGI - Instituto de Engenharia Mecânica e Gestão Industrial \\ Rua do Barroco, 174 4465-591 Leça do Balio (Portugal) \\ phone: +351 229578 716, fax: +351 229537 352, e-mail: miguel.ferreira@inegi.up.pt. \\ ${ }^{3}$ FEUP - Faculdade de Engenharia da Universidade do Porto \\ Rua Roberto Frias, 4200-465 Porto (Portugal) \\ phone: +351 225081 763, fax: +351 225081 440, e-mail: hrodrig@fe.up.pt.
}

\begin{abstract}
The seasonality and variability of the wind regime cause the wind farms to operate during a significant part of time in partial load regime and sometimes with very low load factors. In Portugal, the permission to the connection to the electrical grid is given in terms of nominal power. Consequently the installable capacity is limited and the productive capacity is only used during a reduced number of hours per year.
\end{abstract}

Even installing a bigger capacity then the grid limitation, only in small periods the power output would exceed that value. It should then be necessary to shut down some of the turbines or, by any mean, to limit the output of the wind farm. In return, during large periods, the excess in capacity will permit to increase the energy production and the wind farm income.

The determination of the periods when the wind farm load imposes that one or more turbines should be shut down is not evident, when studying wind farms operating in complex terrain sites. In these regions, the load of each wind energy converter will vary according to the wind velocity and orientation, being usual to find large differences of load factor over short distances.

Furthermore, the determination of the optimum capacity in these situations cannot be separated of the investment costs of increasing the nominal power installed. An economical analysis has to be associated to the productivity calculations, in order to determine the ideal solution from the project economical performance point of view.

This work presents a test case based in a methodology developed to support the project optimization of wind farms with limitations in the power to be delivered to the grid.

\section{Key words}

Power limitation, over-capacity, annual production, capacity optimisation, economical ratios.

\section{Introduction}

The coincidence of profitable wind potential with weak grid zones makes the low capacity to evacuate the produced electricity an important barrier to the penetration of wind energy in Portugal. In fact, most of the wind potential in the country is concentrated in remote areas, of great altitude, where one can take advantage of the accelerating effects over the wind flow originated by the complexity of the relief. There, the population density is usually low and, therefore, energy consumption is low. As a result, the power lines have reduced capacity. It is also known that the seasonality and variability of the wind regime leads wind turbines to operate at low load factors, during a significant part of the time.

Due to the nature of the wind resource, there will be a considerable amount of time in which the turbines will even stay stopped. At low wind conditions, for example, the turbines located in the top of the hills can be in operation, while other, located at lower altitude or shadowed, can be stopped. In the same way, for speeds above $20 \mathrm{~m} / \mathrm{s}$, bursts above $25 \mathrm{~m} / \mathrm{s}$ can happen in the highest places, some of the turbines beginning to cut off, while others, more sheltered by the relief, can stay in operation.

The permission for grid connection is given in terms of nominal power. On one side, the power to install is limited; on the other side the producing capacity is only fully used during a reduced number of hours per year.

This situation is being analysed for some time, with promoters considering the installation of over capacity, in order to compensate for the low load factors. Some wind 
farms already installed in Portugal are in this situation, even if no one is sure about the real impact of the option on the project profitability. The grid operator imposes the power limitation shutting down the wind farm if the output power is over passed. The wind farm operator can, on his side, control power output, to avoid shutting down, by stopping one or more turbines, or, in the case of pitch controlled wind turbines, limiting the power output of machines.

During the project phase, the definition of the ideal capacity of a wind farm to be installed, in these conditions, is not evident. The target is, off course, to maximise the profitability of the project. Even if it is consensual that some degree of overcapacity benefits project value, quantifying that overcapacity is not an easy matter, especially when the wind farm is to be implemented in a non-homogeneous terrain, with the wind turbines delivering different outputs for a given wind condition.

A main problem that arises when looking for the optimisation of the capacity of a wind farm in this context is the simulation of the wind farm operation. Several approaches exist, but no one is of quick and easy use. The difficulty of the analysis of a site's wind regime in this perspective has to be considered, as well as the spatial variability of the resource that is normally present in complex terrains.

\section{Previous work, scope and objective}

In a study previously carried out [1], [2] it was attempted to build a methodology supporting the project optimisation of grid delivery limited wind farms. It was then shown that the results of the methodology in what concerns power output prediction of the wind farm for a given wind regime, are in good agreement with the reality.

This work aims to be a step ahead on this methodology. This paper focuses on the following topic of the work, with the methodology being only briefly remembered. The final part of the methodology, the one concerning the capacity optimisation resulting from the consideration of the economical aspects, is now included and the optimisation of the capacity of a wind farm achieved.

\section{Economical capacity to install - Global methodology}

There are different aspects to consider, related with the capacity to install in a wind farm, when a limitation in the power to be delivered to the grid exists: the increase of the number of wind turbines leads to larger investment costs; at wind velocities below the ones corresponding to nominal power, the energy output of the wind farm will increase with the number of turbines; not all the turbines can run at full power simultaneously, due to the power limitation imposed.
The capacity installed in conditions of maximum project profitability will result, normally, of a compromise solution between investment costs and annual revenue. The optimum solution is to be selected after the analysis of economical ratios, such as the Net Present Value, NPV, or the Internal Rate of Return, IRR.

The determination of this optimum point is made iteratively, varying the installed capacity of the wind farm and calculating the corresponding economic indicators.

\subsection{Productivity calculation}

In the methodology described in [1], the estimate of the wind farm production is obtained defining a group of situations in which the wind speed and direction at the measuring station is fixed. For each of those situations the power output of each turbine is evaluated. Knowing the probability of occurrence associated with a particular situation, it is possible to foresee the annual production of each turbine and, consequently, the wind farm energy yield.

If the power output of the wind farm exceeds the imposed grid limitation, some turbines must be regulated to control its power output (pitch controlled or variable rotational speed machines) or stopped (stall controlled machines), in a way that total wind farm power does not exceed the limit figure.

\subsection{Economical analysis}

The optimisation procedure starts with the economical analysis of the project for the maximum number of turbines that can be installed in the site. Several items are considered as terrain availability, constraints and restrictions, as well as the minimum resource level previously defined to select a position for the installation of a wind turbine.

In order to compute the revenue, the specific tariff scheme has to be taken into account. In the Portuguese case, the capacity of the wind farm, and the percentage of energy produced in the diurnal period are considered in the valorisation of the production. Additionally, the level of the annual energy yield of the wind farm is of great importance: the first 2000 equivalent hours at full capacity are paid at the highest price, the remuneration being reduced for steps of 200 hours, up to 2600. Beyond this limit the energy is paid at a less interesting price. The calculation of the equivalent hours is performed with reference to the nominal power of the wind farm.

In order for the comparison of the project profitability with different installed capacities to be done, the model considers an increase of costs based on the number of installed turbines. The investment costs with the turbines, the electrical and civil infrastructures or the operation and maintenance costs are among the variables that are dependent on the installed capacity. 
After the introduction of the reference costs for turbines the structure of the financing the project is inserted, as well as taxes as other charges to paid.

Finally, in order to define the actualisation rate, the economical environment should be characterised. Factors like inflation or the risk margin accepted by the investors is to be considered in this point.

Performing a cash flow analysis, the economical ratios are calculated. The methodology uses the NPV as the main indicator of the economical value of the project.

The following step is to remove turbines and proceed to a new evaluation of the project, now with smaller installed capacity. There are several criteria to choose the turbines to be eliminated; for example the most distant, in order to minimise the construction costs, or the less productive ones. In this case, the chosen approach was the productivity, due to the fact that, in projects of this type, the decisive variable is, normally, the energy yield. Obviously, the production of the park in this new configuration will decrease, but also the cost will.

The new NPV is compared with the previously obtained figures. The process is then repeated, including the calculation of the wind farm energy yield, as it is dependent on wake effects, the target being to obtain for this ratio the maximum possible value. The expected variation of the NPV in function of the installed capacity is presented in figure 1 . The optimum capacity to install is easily detectable since it corresponds to the point of inflection of the curve.

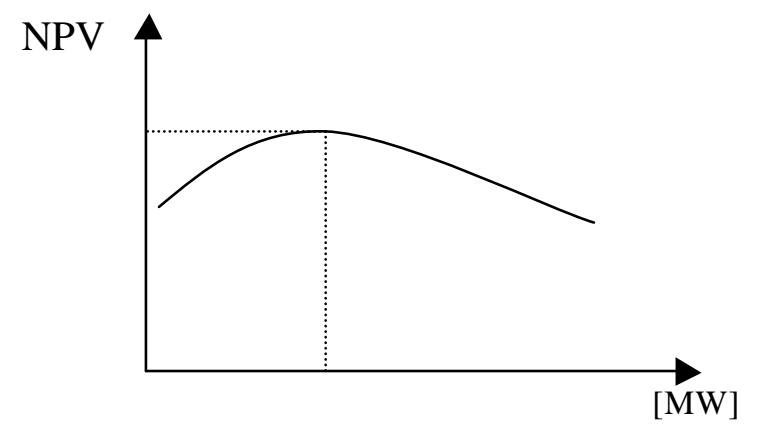

Figure 1 - Curve of the determination of the optimum capacity to install

\section{Test case}

The methodology reported in the preceding sections is being tested in several wind farm projects. One is the Fonte da Mesa wind farm, erected in a mountain in the North of Portugal, Serra das Meadas. 17 turbines of $600 \mathrm{~kW}$ each constitute the wind farm.

The Meadas mountain develops according to the direction SSW-NNE, from the end North of the Montemuro mountain to the Douro valley. The mean altitude is approximately 1100 meters. To East, the mountain goes down in steep slope until the valley of the Balsemão River.
With the objective of testing the methodology and evaluate the viability of over equipping this $10,2 \mathrm{MW}$ wind farm, installing an higher capacity than the contracted with the grid owner, the hypothesis of installing three additional turbines was considered. Overall capacity would thus be increased to $12 \mathrm{MW}$.

A 3D illustration of the terrain with the implantation of the wind farm is shown in figure 2. Besides the representation of the topography and the indication of the turbine sites (black dots) it is also represented the resource distribution and the tree new sites (white dots).

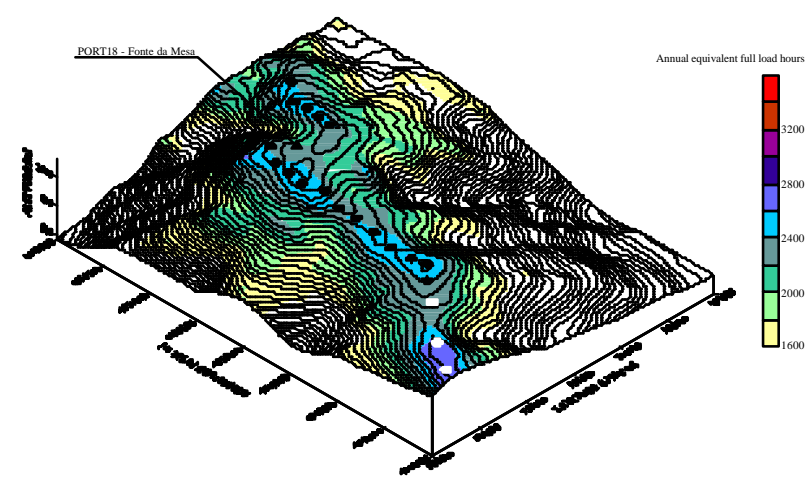

Figure 2 - Tri-dimensional view of the mountain, with the turbines location

The selection of the maximum number of new turbines and their sites was done considering the available area and exclusion criteria, namely environment restrictions and the slope of the terrain. The criteria adopted here was to exclude slopes in excess of $25 \%$. For steeper slopes the turbines will operate under conditions that they were not built for, increasing maintenance needs and reducing lifetime.

Initially, an estimation of the 20 turbines wind farm energy yield was performed using $\mathrm{WA}^{\mathrm{s}} \mathrm{P}$ programme and the European Wind Atlas methodology. This calculation leads to an estimation of the wind farm production of $28040 \mathrm{MWh} /$ year, that was taken as a control value for the result of the methodology.

Briefly remembering the methodology, the wind farm production is evaluated after the instantaneous power output for a series of wind conditions, velocity and direction, covering all the sectors of the wind rose and velocity range. The results are weighted afterwards with the probability of a certain specific condition (velocity and direction) to occur during the year [1], [2]. The final result was an estimation of $26882 \mathrm{MWh}$.

Comparing the results of the two approaches a difference of $4 \%$ was found.

The topographic model used in $\mathrm{WA}^{\mathrm{s}} \mathrm{P}$ can induce errors reaching $15 \%$ in complex terrain [3]. Therefore, the $4 \%$ difference in the production estimation obtained by the methodology developed for this purpose seems to be inside reasonable limits. 
The next step is the consideration of the power limitation. The specific wind situations in which the power limitation of the wind farm is to be exceeded are identified; the output power of the wind farm is forced to the limiting value. This operation leads to a matrix [2], which the sum of all elements, gives the production estimation of $25741 \mathrm{MWh}$.

The energy production was then transposed to the economical model and the first pair energy production / NPV is determined. Successive iterations on this methodology permit to build the graphic energy production/NPV and to find the best economical solution.

Results have shown that, for the test case analysed in this work, the optimal solution is the one that considers $12 \mathrm{MW}$ of nominal capacity, as can be show in the figure 3 .

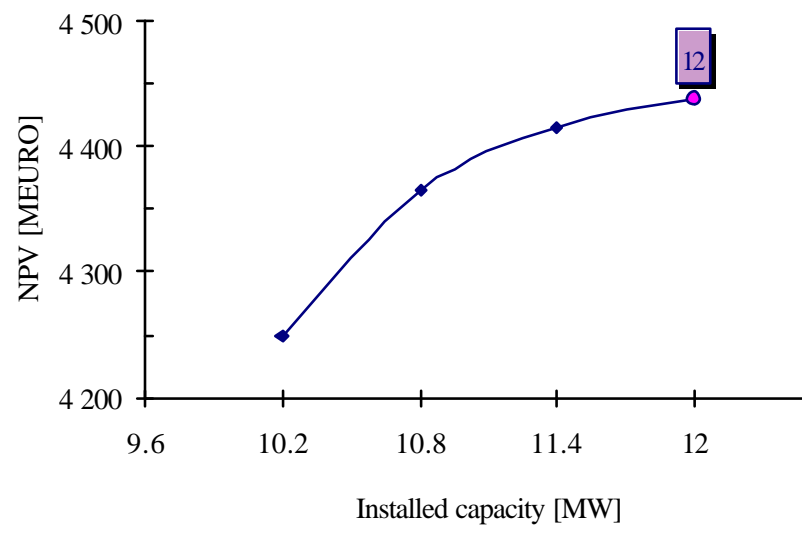

Figure 3 - NPV evolution as function of installed capacity

The inflection point of the curve could not be reached, but the trend is obvious. If the available terrain was larger, allowing the installation of one or two additional turbines, the NPV would probably decrease after the $21^{\text {st }}$ or $22^{\text {nd }}$ turbine.

\section{Conclusions}

The objective of this work was to build a tool aiming the determination of the optimum capacity of a wind farm to be implemented in a given place, subjected to power limitations.

Different factors influence the final solution in this optimisation process, each case being a different one.

A first aspect is the number of wind turbines that integrate the wind farm. It is obvious that the higher is the number of wind turbines of the same type, the margin for installing additional machines, as over-capacity, increases.

There are two reasons for that. One is concerned with the fact that in wind farms with a larger number of turbines, occupying a large non-homogeneous area, not all machines are running at full power simultaneously, this situation being expected to occur rarely. The other one is related to the fact that adding a wind turbine to a big number of already existing machines, most of the time the output of the wind farm will not exceed the power limitation.

For the test case here presented, the Fonte da Mesa $17 \times 600 \mathrm{~kW}$ wind farm, the results are in good agreement with the ones obtained with the reference program $\mathrm{WA}^{\mathrm{s}} \mathrm{P}$. The comparison was done for a case where 3 additional turbines were assumed, with the wind farm working without any power limitation. The difference between the two results was found to be about $4 \%$.

When the limitation to the $10,2 \mathrm{MW}$ is imposed, a reduction of $4,2 \%$ in the annual energy yield of the wind farm is obtained, from $26882 \mathrm{MWh}$ to $25741 \mathrm{MWh}$. This production is about $11 \%$ higher than the one estimated for the wind farm in the present configuration.

It was found that the installation of the 3 additional turbines, the maximum that the available area allows, is the optimum solution, leading to the highest NPV value. Nevertheless, if more area could be used, 21 or even 22 turbines could lead to a more profitable project.

The economical criteria with which the investment is evaluated are very important for the decision of the optimum capacity to install. Some tests using different economical ratios for the estimation of the Fonte da Mesa optimum capacity were performed. Those tests proved that different solutions can be found, depending oh the economical evaluation criteria. For example, if IRR is considered, instead of NPV, the optimum solution in Fonte da Mesa is the installation of two more turbines, instead of three.

Installing additional capacity in a wind farm subjected to power limitations can be of interest, but the determination of that extra capacity is not an easy task. The complexity of the site strongly increases the difficulties, and the simplified approaches, assuming a similar output for all the turbines can lead to significant errors. It is believed that the methodology here presented can give better estimates of the benefit obtained with this type of solutions, being an useful tool in the project and operation of wind farms.

\section{References}

[1] P. Pinto, A. Rodrigues, M. Ferreira, F. Castro. Defining the optimum capacity of a wind farm according to grid limitations. EWEC 2001, Copenhagen.

[2] P. Pinto, Projecto e Operação de Parques Eólicos com Excedente de Potência Instalada. MSc thesis. 2001, Porto.

[3] N. Mortensen, L. Landberg, I. Troen, Erik Petersen. Wind Atlas Analysis and Application Program (WASP). 1993. 